http://jmscr.igmpublication.org/home/ ISSN (e)-2347-176x ISSN (p) 2455-0450

crossref DOI: https://dx.doi.org/10.18535/jmscr/v9i5.09

Journal Of Medical Science And Clinical Research

\title{
The functional outcome of closed fracture proximal third of tibia (Extra- articular) treated by MIPO technique using locking plate
}

\author{
Authors \\ Dr A.T. M. Rezaul Karim', Dr A. K. M. Harun-Ar-Rashid², Dr Abdur Rahman', \\ Dr Mohammad Shaha Alam ${ }^{4}$, Dr Ayesha Begum ${ }^{5}$, Dr A. H. M. Azgar Ali Chowdhury 6 \\ ${ }^{1}$ Consultant of Orthopedic Surgery, Parkview Hospital, Chattogram, Bangladesh \\ ${ }^{2}$ Assistant Prof. of Orthopedic Surgery, Cox's Bazar Medical College, Cox’s Bazar, Bangladesh \\ ${ }^{3}$ Assistant Prof. of Orthopedic Surgery, Chattogram Medical College, Chattogram, Bangladesh \\ ${ }^{4}$ Assistant Prof. of Surgery, Cox's Bazar Medical College, Cox's Bazar, Bangladesh \\ ${ }^{5}$ Assistant Prof. of Pediatrics. Chattogram Medical College, Chattogram, Bangladesh \\ ${ }^{6}$ Junior Consultant of Orthopedic Surgery, Chattogram Medical College Hospital, Chattogram, Bangladesh \\ *Corresponding Author
}

\section{Dr A.T. M. Rezaul Karim}

\begin{abstract}
Objective: In this study our main goal is to evaluate the functional outcome of closed fracture proximal third of tibia (Extra- articular) treated by MIPO technique using locking plate.

Method: This observational study was carried out at Department of Orthopaedic Surgery, Chattogram Medical College Hospital; Chattogram, From January 2012 to June 2013. A total of 26 patients within 1860 years of age and were admitted in different Orthopaedic units of Chattogram Medical College Hospital with closed fracture in proximal tibia were included in the study.

Results: During the study, 4 patients (17.40\%) have additional injuries. Nearly half of them (2 cases) were victims of head injury. Then rest 1 case involving with ipsilateral femur fracture, another 1 case involving with ipsilateral bi-malleolar fracture. 21 of the patients were mobilized by active knee bending and quadriceps exercises were initiated after second week. 2 patients associated with other injuries mobilization were delayed. In 15 cases (65.22\%) full range of knee motion at 12 weeks. 6 cases had good results (26.09\%), 2 fairs (8.70\%).In 18 cases (78.26\%) full range of ankle motion at 12 weeks, 3 cases had good results (13.04\%), 2 fairs (8.7\%). According to patient's satisfaction 14 patients (60.87\%) was pleased, 7 patients $(30.43 \%)$ was satisfied and two patient $5 \%$ is unhappy.

Conclusion: Proximal tibial fracture is common fracture of the tibia. There are several methods of treating this fracture. In case of proximal tibial fractures, closed reduction and internal fixation with locking plate is a good choice. Most importantly, it is easy to use, it is biological in the sense that the blood circulation to the tibia is not compromised, the plate does not need to be configured and the angular screw fixation ensures a fixed-angle stabilization.

Keywords: Closed fracture proximal third of tibia, MIPO technique, locking plate.
\end{abstract}

\section{Introduction}

Tibia is the most subcutaneous long bone of the body which is susceptible to injury and fracture. Fractures of the proximal third of tibia can be challenging to treat because of the limited soft tissue and the subcutaneous location. The best treatment remains controversial and debatable. ${ }^{1}$ Non-surgical treatment is possible for stable 
fractures with minimal shortening, but malunion, angulation, shortening of affected leg, limitation of range motion and early osteoarthritis because of malunion of the knee have all been reported following treatment of those fractures. ${ }^{2}$

Surgical fixation of the proximal third tibia fractures can be difficult and requires careful preoperative planning. Fracture pattern, soft tissue injury and bone quality critically influence the selection of fixation technique. Several surgical methods have been described, including external fixation, intramedullary nailing, and plate fixation. ${ }^{3}$ External fixation can be useful in open fractures with soft tissue injury which preclude nail or plate fixation, but may result in inaccurate reduction, a relatively high rate of malunion and pin tract infection. ${ }^{4}$

In diaphyseal fractures of the tibia, intramedullary closed nailing allows relatively atraumatic closed stabilization. It preserves the vascularity of the fracture site and integrity of the soft tissue envelope. ${ }^{5}$ However, stable an intramedullary nailing of the proximal tibia may be difficult to achieve because the hourglass shape of the intramedullary canal prevents a tight endosteal fit and compromises torsional and angular stability. ${ }^{\mathbf{6}}$ MIPO is a modern concept of fracture fixation. It aims to preserve the biology of tissue at the fracture site, to maximize the healing potential of the injured bone, soft tissue, and to facilitate early pain free recovery. This is achieved by carrying out the procedure without exposure of the fracture site and by introducing the plate in a submuscular, epiperiosteal position with minimal disturbance of vascularity of the bone fragments. ${ }^{7}$

In this study our main goal is to evaluate the functional outcome of closed fracture proximal third of tibia (Extra- articular) treated by MIPO technique using locking plate.

\section{Objective}

To asses the functional outcome of closed fracture proximal third of tibia (Extraarticular) treated by MIPO technique using locking plate.

\section{Methodology}

Type of study: This was an observational study.

Place and period of study: This study was carried out at Department of Orthopaedic Surgery, Chattogram Medical College Hospital, Chattogram, From January 2012 to June 2013.

Study population: All the patients were within 18-60 years of age and were admitted in different Orthopaedic units of Chattogram Medical College Hospital with closed fracture in proximal tibia. For diagnosis AO classification of proximal metaphyseal and proximal shaft fracture of tibia was used. Cases were selected purposively.

Sample Size: Total 26 patients were enrolled in the study. Three patients were lost to follow-up. So, finally 23 patients were available for evaluation.

\section{Inclusion Criteria}

$>$ Age $-18-60$ years

$>$ Sex - patients were selected irrespective of sex.

$>$ Site - Fractures of the proximal metaphysis and proximal diaphyseal fracture of tibia.

$>$ Closed fracture.

$>$ Those fractures in which initial conservative management for soft tissue injury.

$>$ within 2 weeks of initial injury.

\section{Exclusion Criteria}

$>$ It excludes patients of age less than 18 years and more than 60 years.

$>$ Type of fracture

- Open fracture

- Diaphyseal fractures extending into middle and distal third.

- Fracture associated with neurovascular injury.

- Pathological fractures.

\section{Preoperative Preparation}

Patient was consulted regarding the treatment procedure with emphasis on the available treatment options along with merits and demerits of each. He/she was also being informed about the possible postoperative sequels. Informed written 
consent was obtained from each case included in the study. All issues regarding the patients' welfare were approved by the local ethical committee.

\section{Data Analysis}

Collected data were analysed using software SPSS (Statistical Package for Social Sciences) version 23 for windows. Descriptive and inferential statistics were used to analyse the data. Analysed data were presented in the form of tables and charts with due interpretation.

\section{Results}

In table-1 shows age distribution of the patients. The study population included 23 patients, who ranged in age between 18 years and 60 years (average 35.43 years). The mean age for males was 36.35 years whereas the mean age for females was 32.83 years. The maximum incidence occurred between 21 and 40 years with $78 \%$ of cases occurring in patients before their fifth decade. The following table is given below in detail:

Table 1 Age distribution of the patients $(n=23)$

\begin{tabular}{|l|c|c|c|}
\hline Age (Yrs) & Frequency & Percentage & Mean age \\
\hline $16-20$ & 0 & $0 \%$ & \\
\cline { 1 - 2 } $21-30$ & 7 & $30.43 \%$ & \\
\hline $31-40$ & 11 & $47.83 \%$ & \multirow{2}{*}{35.43} \\
\hline $41-50$ & 3 & $13.04 \%$ & \\
\hline $51-60$ & 2 & $08.70 \%$ & \\
\hline
\end{tabular}

Figure-2 shows sex Distribution. Most (73.91\%) of the patients were male and the rest $(26.09 \%)$ were female, giving a male to female ratio of roughly $4: 1$. The following table is given below in detail:

Table-2: Sex Distribution

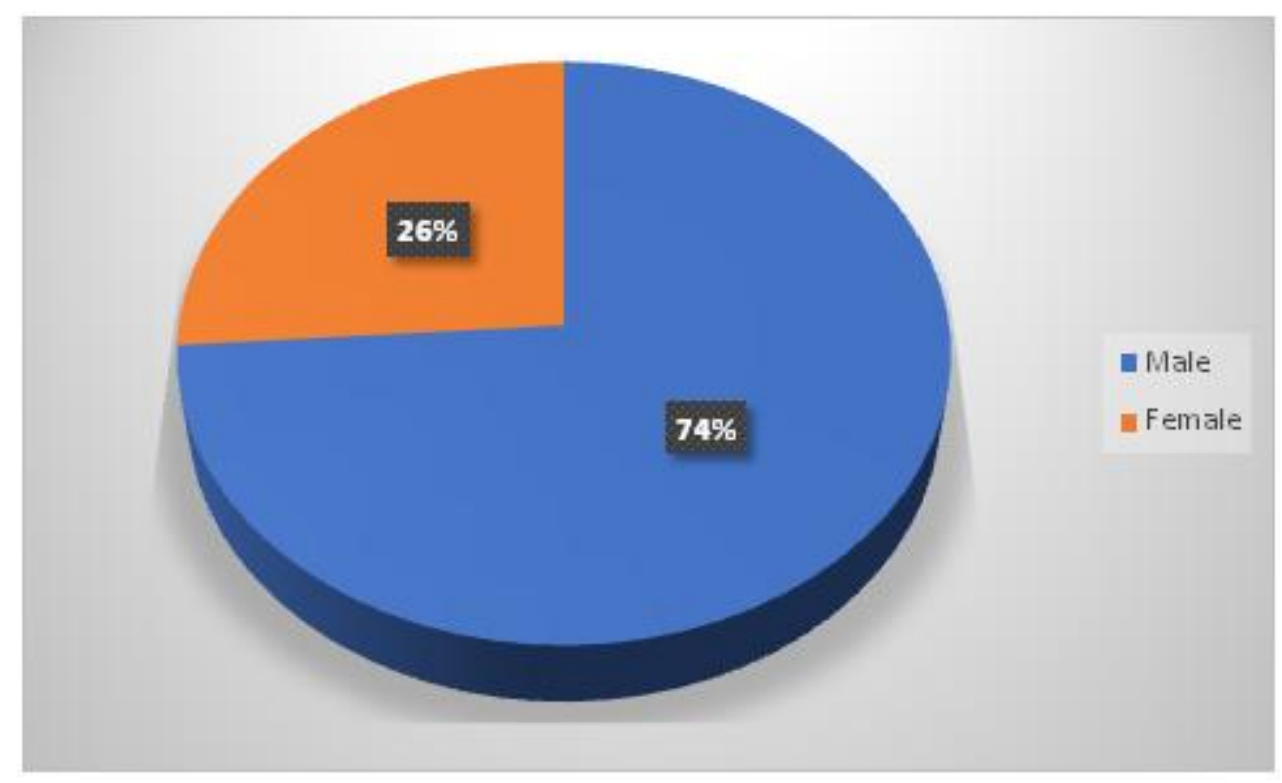

In table-3 shows associated injuries. From the

23 patients included in this study, 4 patients $(17.40 \%)$ have additional injuries. Nearly half of them ( 2 cases) were victims of head injury. Then rest 1 case involving with ipsilateral femur fracture, another 1 case involving with ipsilateral bi-malleolar fracture. The following table is given below in detail: 
Table- 3: Associated Injury

\begin{tabular}{|c|c|c|c|c|}
\hline \multirow[t]{2}{*}{ Associated injuries } & \multirow{2}{*}{$\begin{array}{l}\text { No. of } \\
\text { cases }\end{array}$} & \multicolumn{2}{|c|}{ Side effected } & \multirow[t]{2}{*}{ Treatment given } \\
\hline & & Rt. & Lt. & \\
\hline Head injuries & 2 & - & - & Conservatively treated \\
\hline $\begin{array}{l}\text { With ipsilateral femur } \\
\text { fracture }\end{array}$ & 1 & 1 & - & Operative treated \\
\hline $\begin{array}{l}\text { With ipsilateral bi- } \\
\text { malleolar fracture }\end{array}$ & 1 & - & - & Operative treated \\
\hline
\end{tabular}

In table- 4 shows fracture union according to $\mathrm{AO}$ classification. Multifragmentary Type $\mathrm{C}$ fractures united after a mean time of 28.33 weeks (range,
24-31 weeks). Delayed union occurred in 2 out of 3 patients. The following table is given below in detail:

Table -4 Fracture union according to AO classification

\begin{tabular}{|c|cc|c|c|}
\hline Type of fracture & \multicolumn{2}{|c|}{ Union } & Delayed union & Non union \\
\hline A & $20.45 \quad$ weeks & 1 & 0 \\
\hline B & 23.0 & weeks & 0 & 0 \\
\hline C & 28.33 weeks & 2 & 0 \\
\hline
\end{tabular}

In table-5 shows range of movement in knee. One of the essential aspect of closed reduction and internal fixation with locking compression plate is the ability to mobilize the patient early. 21 of the patients were mobilized by active knee bending and quadriceps exercises were initiated after second week. 2 patients associated with other injuries mobilization were delayed. In 15 cases $(65.22 \%)$ full range of knee motion at 12 weeks. 6 cases had good results (26.09\%), 2 fair (8.70\%). The following table is given below in detail:

Table -5: Range of movements in knee

\begin{tabular}{|l|c|c|}
\hline Knee motion & 12 weeks & Percentage \\
\hline Excellent (full) & 15 & $65.22 \%$ \\
\hline Good $\left(<25^{\circ}\right.$ loss $)$ & 6 & $26.09 \%$ \\
\hline Fair $\left(25^{\circ}\right.$ loss $)$ & 2 & $8.70 \%$ \\
\hline Poor $\left(>25^{\circ}\right.$ loss $)$ & 0 & $0 \%$ \\
\hline
\end{tabular}

In table- 6 shows range of movement in ankle. In 18 cases $(78.26 \%)$ full range of ankle motion at 12 weeks, 3 cases had good results (13.04\%), 2 fair
(8.7\%). The following table is given below in detail:

Table 6: Range of Movements in Ankle

\begin{tabular}{|l|c|c|}
\hline Ankle motion & 12 weeks & Percentage \\
\hline Excellent (full) & 18 & $78.26 \%$ \\
\hline Good $\left(<25^{\circ}\right.$ loss $)$ & 3 & $13.04 \%$ \\
\hline Fair $\left(<25^{\circ}\right.$ loss $)$ & 2 & $8.7 \%$ \\
\hline Poor $\left(<25^{\circ}\right.$ loss $)$ & 0 & $0 \%$ \\
\hline
\end{tabular}

In table-7 shows functional outcome. In 11 cases (47.82\%) had excellent results. 9 cases had good results $(39.13 \%)$ and three cases $(13.04 \%)$ fair result. The following table is given below in detail: 
Table -7: Functional Results (Klemm And Borner, 1986)

\begin{tabular}{|l|c|c|c|}
\hline Result & Group & No of patient & Percentage \\
\hline \multirow{3}{*}{ Excellent } & Fresh cases & 6 & $26.08 \%$ \\
\cline { 2 - 4 } & Delayed cases & 5 & $21.73 \%$ \\
\hline \multirow{3}{*}{ Good } & Fresh cases & 1 & $4.34 \%$ \\
\cline { 2 - 4 } & Delayed cases & 8 & $34.78 \%$ \\
\hline \multirow{3}{*}{ Fair } & Fresh cases & 1 & $4.34 \%$ \\
\cline { 2 - 4 } Total & Delayed cases & 2 & $8.69 \%$ \\
\hline
\end{tabular}

In table-8 shows Patients satisfactionwhere 14 patients $(60.87 \%)$ was pleased, 7 patients $(30.43 \%)$ was satisfied and two patient $5 \%$ is

Table-8: Patients Satisfaction

\begin{tabular}{|l|c|c|}
\hline Satisfaction & No. of Cases & Percentage \\
\hline Pleased & 14 & $60.87 \%$ \\
\hline Satisfied & 7 & $30.43 \%$ \\
\hline Unhappy & 2 & $8.70 \%$ \\
\hline
\end{tabular}

\section{Discussion}

The results of this study demonstrates, the age of the patients were between 21-60 years, mean age being 35.43 years.Almost similar findings were reported by one study where mean age were 42.5 years and 45 years respectively. ${ }^{9}$ From these studies it is evident that the proximal Tibial fractures in our country seems to occur in relatively middle aged people.

Among 23 patients 17(73.91\%) were male and 06 $(26.09 \%)$ were female. Male-female ratio was approximately $4: 1$. In the study of Hazarika $S$ male-female ratio was $4: 1$ and in the study of 2004, the male-female ratio was 4:1. Male are more effected due to they are more vulnerable to trauma. $^{10}$

Regarding configuration of fracture in this study most of the fracture were AO type A $65.22 \%$ (15). In the study reported that most of the fracture were A type (12) followed C type. ${ }^{11}$

Union was defined as the ability of the patient to bear full weight without support on the injured leg, if other injuries allowed, with no appreciable fracture site pain or tenderness, together with the presence of mature callus bridging the fracture in unhappy. The following table is given below in detail:

at least three of four cortices seen in the anteroposterior and lateral radiographs.

Delayed union (DU) was defined as lack of solid clinical and radiographic fracture union at 26 weeks, whereas non-union (NU) was defined as failure of a fracture to heal within 36 weeks.

In the final follow up, according to criteria by KLEMN and BORNER $^{8}$ scoring system the satisfactory result $86.95 \%$ of which $47.82 \%$ was excellent and $39.13 \%$ good results. $13.04 \%$ was fair result.

The bone healing was excellent with this type of fixation because the stresses were distributed over a longer segment of bone. This technique can be used in fractures where locked nailing cannot be done like vertical slit and markedly comminuted fractures. There was rapid fracture consolidation due to preserved vascularity. There were fewer incidences of delayed union and no non-union. There was no need for bone grafting. There was less incidence of infection due to limited exposure. There were less chances of refracture. With the introduction of Locking Compression Plates (LCP), minimally invasive techniques have become widely used. The plates act as internal 
fixators in a bridging manner, thus resulting in secondary bone healing. ${ }^{12}$

\section{Conclusion}

Proximal tibial fracture is common fracture of the tibia. There are several methods of treating this fracture. In case of proximal tibial fractures, closed reduction and internal fixation with locking plate is a good choice. Mostimportantly, it is easy to use, it is biological in the sense that the blood circulation to the tibia is not compromised, the plate does not need to be configured and the angular screw fixation ensures a fixed-angle stabilization.

\section{References}

1. Hazarika S, Chakravarthy J, Cooper J.et al. Minimally invasive locking plate osteosynthesis for fractures of the distal tibia-results in 20 patients.Injury 2006 Sep;37(9):877-87.

2. Sarmiento A, Latta LL. 450 closed fractures of the distal third of the tibia treated with a functional brace. Clin Orthop Relat Res 2004 Nov;(428):261-71.

3. Bedi A, Le TT, Karunakar MA.Surgical treatment of nonarticular distal tibia fractures. J Am Acad Orthop Surg 2006 Jul;14(7):40616.

4. Anglen JO.Early outcome of hybrid external fixation for fracture of the distal tibia.Journal of Orthopaedic Trauma 1999; 13(2):92-7.

5. Blachut PA, O'Brien PJ. Meek RN, et al., Interlocking intramedullary nailing with and without reaming for the treatment of closed fractures of the tibial shaft. J Bone Joint Surg 1997;79A:640-6.

6. Drosos G, Karnezis IA, Bishay M, Miles AW. Initial rotational stability of distal tibial fractures nailed without proximal locking: the importance of fracture type and degree of cortical contact.Injury 2001 Mar; 32(2):13743.
7. Babst R, Bavonratanavech S, Pesantez R. Minimally Invasive Plate Osteosynthesis. 2nd ed. Davos (Switzerland): Thieme Medical and Scientific Publishers Private Ltd; 2012. P. 8.

8. Baumann P, Ebneter L, Giesinger K, Kuster MS. A triangular support screw improves stability for lateral locking plates in proximal tibial fractures with metaphyseal comminution: a biomechanical analysis. Arch Orthop Trauma Surg2011;131:815-21.

9. Francois J, Vandeputte G, Verheyden F, Nelen G. Percutaneous plate fixation of fractures of the distal tibia. ActaOrthop Belg. 2004 Apr; 70(2):148-54.

10. Farouk O, Krettek C, Miclau T, Schandelmaier P, Guy $\mathrm{P}$, Tscherne H. Minimally invasive plate osteosynthesis and vascularity: preliminary results of a cadaver injection study. Injury. 1997;28 Suppl 1:A712.

11. Collinge CA, Sanders RW. Percutaneous plating in the lower extremity. Am AcadOrthop Surg. 2000 Jul-Aug;8(4):211-6.

12. Neeraj Mahajan. Minimally Invasive Techniques in Distal Tibial Fractures. JK SCIENCE Vol. 10 , April-June 2008. 